\title{
Government support of small businesses in the 2020 crisis conditions from the market approach viewpoint
}

\author{
E.R. Zakirova ${ }^{1}$, N. Yu. Lebedeva ${ }^{2}$, and N.V. Pogosyan ${ }^{2}$ \\ ${ }^{1}$ Ural State University of Economics, March 8, 62/45, 620144 Ekaterinburg, Russia \\ ${ }^{2}$ Southern Federal University, Bolshaya Sadovaya Str., 105/42, 344006 Rostov-on-Don, Russia
}

\begin{abstract}
The paper offers a situational overview of small business as a driver of economic growth in Russia during the 2020 crisis and the main aspects of current state policy on market-based support of that sector. The analysis also highlights major barriers that have arisen lately impeding the efficiency of governmental efforts to support small business. However, new aspects stimulating business development in market economy emerge together with the obstacles.
\end{abstract}

\section{Introduction}

The current economic environment (complicated by the COVID-19 pandemic and affected by the 2020 crisis also triggered by the restrictions of forced governmental responses) has definitely influenced the activities in various sectors of Russian economy. Let us review specifically small business as a growth driver, consider the governmental support steps, and reveal the barriers limiting these efforts, in particular those resulting directly from imperfection of the digital backbone facilitating their interaction.In accordance with the Forecast of the RF Ministry of Economic Development for the period until 2030, small business is indicated among the most promising drivers of economic growth including implementation of innovative products. In particular, GDP share of small and medium business in Russia in 2019 was $20.3 \%$, i.e. $1 / 5$ of the total volume of produced goods, performed work, and rendered services.Besides generation of products and services, small business sector plays a socially important role creating workplaces. In 2019 small businesses employed $25.6 \%(18.3 \mathrm{mln}$.) of the entire working populationregistered within the time frame. It should be noted as well that small business sector comprising selfemployed entrepreneurs, micro businesses, and small businesses accounts for the majority of people employed in the small and medium business sector. 


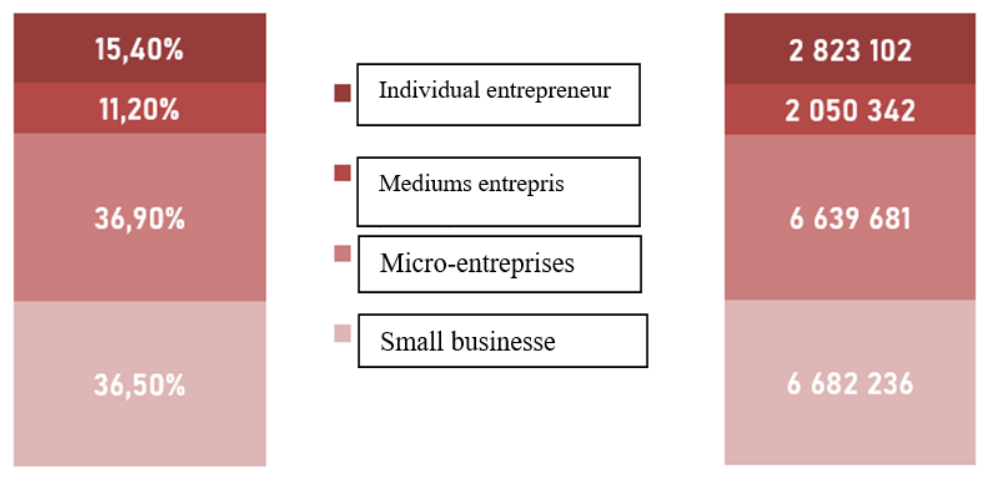

Fig. 1. SME employment structure, 2019 (\%; ppl.)

In the recent years, small businesses have proven to be a sector open to innovations in various areas and intensively using digital technologies to their benefit in ongoing operations. During 2018-2019 the share of small businesses that have experienced innovation effects (implementation and application of innovative products) reached $36-38 \%$ of all entities in that economic sector while in the medium and large business sector innovative changes affected $31-33 \%$ of all the companies. The share of small businesses using digital technologies in at least one aspect was $67.5 \%$ as of January 1, 2020 (in particular, IT in business implies electronic workflow, accounting software, online point-ofsale terminals, etc.), which is significant beyond doubt.Thus, small business is an important sector of Russian economy including its digital environment. Therefore, examining the adverse effects on small business and analyzing the vectors of state policy and barriers thereto currently represent a relevant issue of the day.

\section{Methods and types of the Earth's remote sensing}

Two key peculiarities of crisis conditions should be noted as matters directly affecting small business entities. First, the problem has demand-based nature, i.e. manifestations of the crisis are characterized by a sharp drop of demand in various branches of economy including the falling demand for private goods registered since the process beginning. The second peculiarity is related to the occurrence location. Unlike the financial crisis of 2008, current crisis unfolds directly in the real sector and therefore requires controversial steps necessary to restore the economy.Thus, based on that background, we observe a sharp short-term decrease in the Purchasing Managers' Index (PMI) among small businesses in Russia.

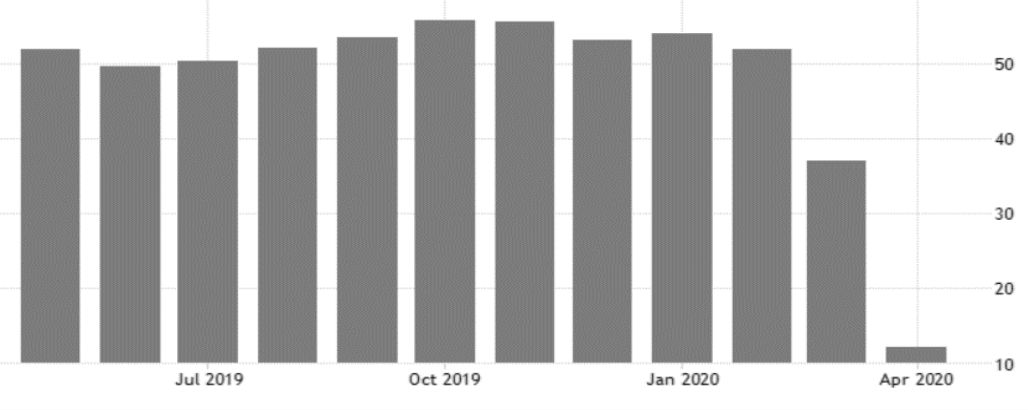

Fig. 2. Russian small business PMI (short-term) 


\section{Analysis of the main ERS data sources for the DEM development}

However, long-term study of the index allows to estimate the depth of the slide in that sector of economy. In this case, business activity falls significantly to a level never observed throughout the last 10 years.

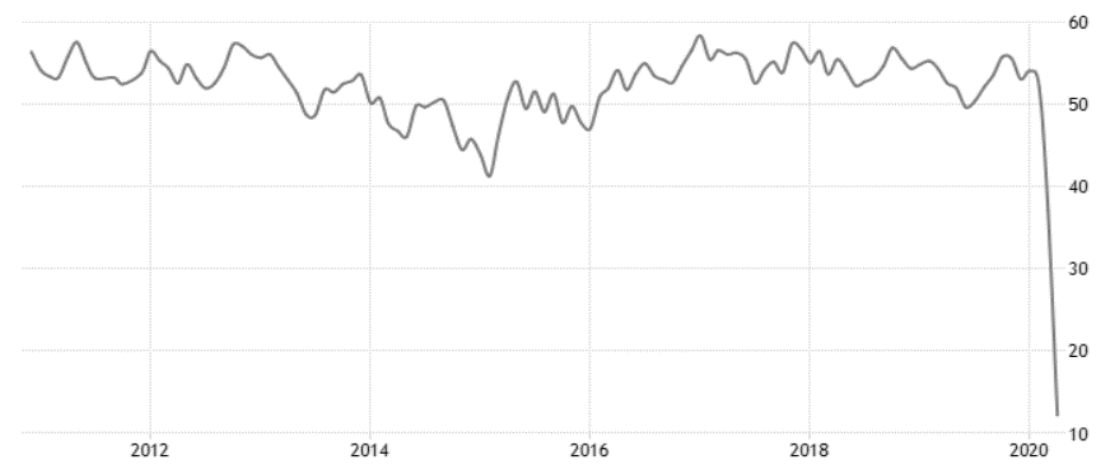

Fig. 3. Russian small business PMI

A drop of retail sales' volume is observed in small business sector. It should be noted at that: $52 \%$ of small businesses are working specifically in retail. Thus, we may assume that a real crisis situation exists in the small business sector.

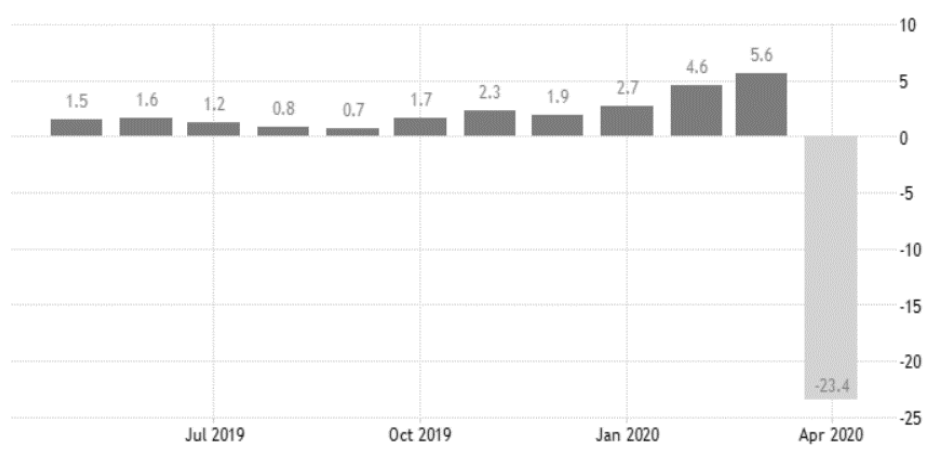

Fig. 4. Small business sales dynamics, $\%$

During analysis of business situation within the economic system and the role of incentives for development including innovation and introduction of digital methods, an essential aspect is represented by the composite leading indicators, which are also exhibiting a drastic drop in the country. Thus, the current environment slows down the process of digital transformation of economy and its participants. 


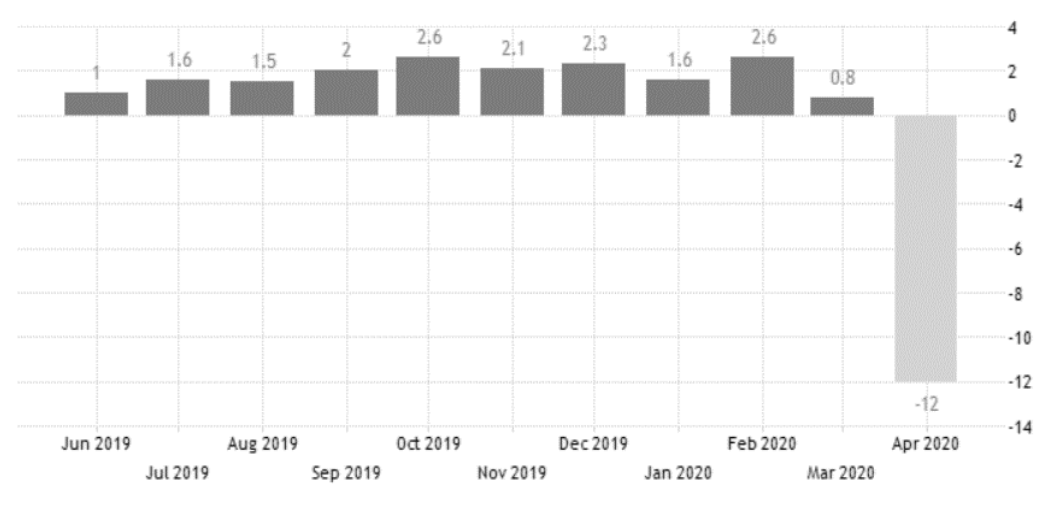

Fig. 5. Russian composite leading indicators

Let us review the state policy for small business support. RF Government Resolution No. 409 'On measures providing for sustainable development of economy' of April 2, 2020, highlights four basic directions of support for small businesses. First, credit and financial support is provided including interest-free loans for current salaries and an opportunity to use discounted loan rates for business credits. Second, reporting for tax purposes is simplified: fewer tax forms are required and the periods for reporting are extended, the number of tax checks and inspection visits is reduced in addition to preferential rates for insurance payments. Benefits related to rental payments for state-owned and municipal property should also be mentioned. Finally, information support is organized providing updates on the changes directly affecting operations of companies.As an important note, the listed support efforts are targeted at - and available only to enterprises of "affected" industries making up just $23 \%$ of all small businesses as their eligibility is also based on the revenue volume. The original list of affected industries covered $18 \%$ of small businesses, the list approved later included only 5\% more. No doubt, the list of affected industries is quite limited because the entire sector suffers from lowering business activity, the volume of retail sales, and decreasing demand.Thus, one cannot but note that manifestations of state support have controversial character including accessibility for affected small business representatives.

In particular, one may note that the policy ignores the specifics of small business operation, such as absence of significant reserve funds and direct dependence of revenues and expenses on the sales volume. Therefore, concessionary loans for salary payments for a few months and extension of tax payment periods appear to be a "trap" because small businesses have no available reserve funds to use and cannot ensure future accumulation of funds to cover the outstanding dues.Second, there is a considerable time gap between approval of support vectors and efforts and the establishment of relevant eligibility requirements to the support recipients. As a result, some small businesses anticipating further aggravation of the situation in advance minimized their expenses including salary payments. Consequently, only a small part of potential recipients was able to use the support.Finally, the support request procedure is evidently lacking a clear algorithm that the applicants could use and remains quite bureaucratic in character.

In confirmation of the controversies revealed, allow us to present the structure of small businesses arranged according to their ability to procure the support based on statistical data. Only $3.1 \%$ of companies in affected industries were able to receive at least one kind of benefits or support, making up to approximately $0.71 \%$ of the total number of small businesses. A significant number of requests was declined because of ineligibility based on the existing requirements. Quite a lot of companies also decided to forfeit their right to apply for support, probably, because they realized their ineligibility.Thus, there is a 
problem of decreasing business confidence index among small businesses in the short term. However, the business confidence index has not been too high lately, so its decrease is not critical considering the general background.

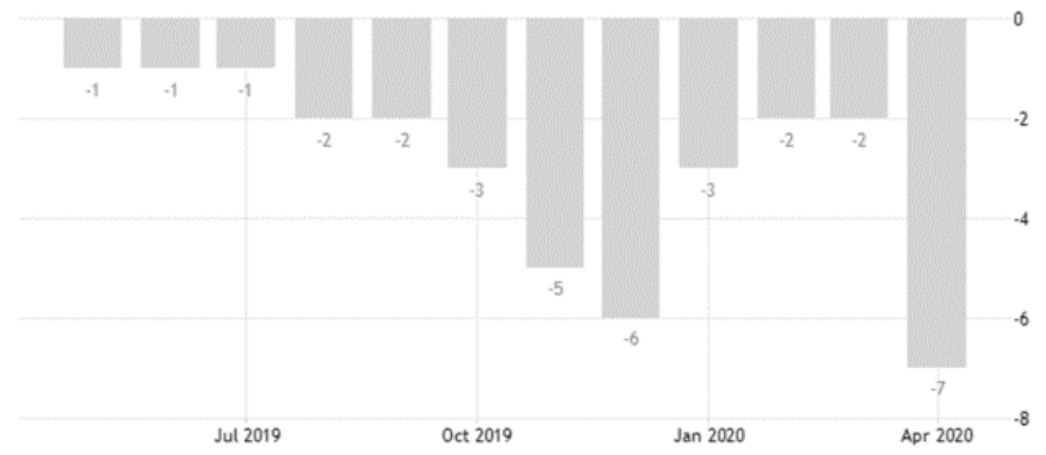

Fig. 6. Russian small business confidence index

\section{Conclusions}

Still, a decrease of small business confidence index may be directly related to the state support entry barriers impeding the efficiency of these efforts.In particular, institutional barriers stand out as obstacles manifested in high transaction costs related to three key aspects. First, this implies the charges of information search because there is no efficient mechanism that can be used to receive the support benefits. Second, the charges include the costs related to the acquisition of special rights within the framework of state support as the procedure takes quite a lot of time because of bureaucratic administration. Finally, the absence of a designated agent on the small business side should be noted. Small businesses do not always have highly skilled financial officers optimizing business processes and minimizing expenses. Thus, the typical staff has no motivation to search for and use the support benefits while the owners in most cases have no required competences. The first two issues are directly related to the problems of the digital system for interaction between small businesses and state authorities. Therefore, these barriers can be eliminatedby taking digital and electronic interactions to a higher level.Among economic barriers, we should underline such aspects as narrow focus of the governmental support efforts combined with hardly comprehensible logic behind the list of affected industries. The second barrier is manifested in the lack of understanding of small business specifics in Russian economy.The former aspect cannot be analyzed independently from the market mechanism acting directly as the foundation of Russian economy; consequently, support of numerous companies during crisis is hardly appropriate because that will decrease the competitiveness of such recipients. It should also be noted that current challenging environment vividly reflects the need for flexibility in business operations. Thus, the situation may encourage discovery of new, more promising and competitive paths for small business development including implementation of IT methods and solutions.

\section{References}

1. On approval of the list of Russian industries most afflicted by the aggravated situation resulting from the coronavirus pandemic: RF Government Resolution No. 434 of April 3, (2020), http://www.consultant.ru/ 
2. On measures providing for sustainable development of economy: RF Government Resolution No. 409 of April 2, (2020), http://www.consultant.ru/

3. On approval of the Rules for subsidizing from the Federal budget in 2020 Russian credit institutions for payment deferrals of loans provided to small and medium businesses: RF Government Resolution No. 410 of April 2, (2020), http://www.consultant.ru/

4. N.A. Mamedova, E.A. Devyatkin, Small business in market environment (2019)

5. Russian SME Resource Center, https://rcsme.ru/

6. Kovalenko K.E., Ling V.V., Individual Entrepreneurship in Russia and Abroad: Social and Legal Aspects, https://www.abacademies.org/

7. V.V. Schneider, Amazonia Investiga, 14, 61 (2018)

8. N.Yu. Lebedeva, Modernization And Development Of The National Economy, materials of the All-Russian scientific and practical conference in the framework of the XXXIX Scientific session of the Faculty of Economics of the Southern Federal University. In two volumes, 291 (2018)

9. I.V. Frolova, N.Yu. Lebedeva, Auditors' statements, 10, S82 (2014)

10. N. Roubini, The Guardian, November 2018

11. W. R. Engert, B.S. Fang, Bank of Canada Staff Discussion Paper 2017-16 (2017)

12. J. Lewis, Economic Impact of Cybercrime - No Slowing Down. Center for Strategic and International Studies (2018) 